\title{
REKOMENDASI KOMPOSISI MATERIAL INJEKSI PENGISI REKAHAN BATUAN, UNTUK MENINGKATKAN KEKUATAN GESER BATUAN BERKEKAR
}

\author{
Rizto Salia Zakri ${ }^{1)}$ \\ ${ }^{1}$ Jurusan Teknik Pertambangan, Universitas Negeri Padang \\ email: riztoszakri@ft.unp.ac.id
}

\begin{abstract}
Abstrak: Masalah umum yang sering ditemukan dalam kegiatan penambangan adalah ketidakstabilan yang disebabkan oleh massa batuan berkekar. Salah satu upaya mencegah ketidaksatbilan pada masa batuan di pertambangan adalah dengan melakukan perkuatan batuan menggunakan injeksi semen. Contoh batuan buatan yang digunakan pada penelitian ini terbuat dari bahan gypsum berjenis moldano tara. Kekasaran permukaan rekahan batuan diperoleh dari rekahan batuan alamiah dan dibagi menjadi tiga kelompok nilai Joint Roughness Coefficient (JRC) berdasarkan kriteria Barton. Sementara, bahan injeksi adalah campuran semen dan air dengan perbandingan air : semen 4: 5 dan 3: 2. Sampel yang sudah injeksi kemudian diuji geser langsung. Hasil pengujian dianalisis dengan kriteria Mohr-Coulomb untuk mendapatkan kohesi dan sudut gesekan dalam. Berdasarkan hasil pengujian ditemukan bahwa peningkatan kekuatan bervariasi berdasarkan kondisi JRC. Untuk Sampel dengan nilai JRC antara 8-10, penelitian ini menemukan bahwa bahan injeksi dengan rasio air terhadap semen 4: 5 lebih efektif daripada injeksi semen dengan rasio 3: 2. Sedangkan untuk nilai JRC antara 12-14, 16- 18, dan 18-20, ditemukan bahwa injeksi semen dengan rasio 3: 2 lebih efektif daripada 4: 5. Dengan kata lain, untuk sampel dengan nilai JRC kecil, material injeksi yang kental akan lebih efektif, sementara untuk JRC besar material injeksi yang encer akan lebih efektif.
\end{abstract}

Kata kunci: Injeksi Semen, Joint Roughness Coefficient, Moldano Tara, Mohr-Coloumb Criteria, Barton-Bandis Criteria

\begin{abstract}
Common problem in mining activity is instability caused by jointed rock mass. The strength of jointed rock mass can be increased by cement injection. An artificial rock sample made from dental plaster type of moldano tara is used in this study to evaluate the influence of cement injection to the strength of jointed rock sample. The roughness of joint surface are obtained from the natural rock joints and divided into three groups of JRC values based on Barton criteria. The injection materials are mixture of cement and water with water and cement ratio of 4: 5 and 3: 2. Direct shear test results are analyzed by Mohr-Coulomb criterion to obtain the cohesion and internal friction angle. As the result the strength increase varies by JRC condition. For Sample with JRC value between 8-10, the study find that injection material with water to cement ratio of 4:5 is more effective than cement injection with ratio of 3:2. For JRC value between 12-14, 16-18, and 18-20, it is found that cement injection with ratio of 3:2 is more effective than 4:5. So, for sample with small JRC value, thicker injection material will be effective. In other hand, sample with high JRC value, thinner injection material will be more effective.
\end{abstract}

Keywords: Cement Injection, Grouting, Joint Roughness Coefficient, Mohr-Coloumb, Joint

\section{PENDAHULUAN}

Permasalahan yang umum pada kegiatan penambangan, adalah masalah ketidakstabilan pada lereng tambang terbuka, maupun pada terowongan penambangan. Pada kondisi asli, masa batuan dipengaruhi oleh struktur dan rekahan yang akan mempengaruhi kekuatan masa batuan. Salah satu upaya yang dapat dilakukan untuk meningkatkan kekuatan batuan adalah dengan menginjeksikan semen ke rekahan batuan yang biasa disebut Grouting. Sejalan dengan peningkatan penggunaan Grouting pada proses penguatan masa batuan, maka penelitian tentang sifat dari Grouting perlu dilakukan untuk mengetahui pengaruh penggunaan Grouting terhadap 
peningkatan kekuatan masa batuan. Grouting adalah sebuah proses penginjeksian material Grouting ke dalam rekahan, pori, atau celah dari sebuah masa batuan atau tanah, yang merubah sifat dari tanah atau batuan tersebut (Nonveiller,1989). Joint merupakan sebuah istilah yang digunakan dalam mekanika batuan yang meliputi semua bidang lemah, kecuali patahan (Arif,1989). Hasil dari grouting akan meningkatkan kekuatan masa batuan dan menurunkan deformasi (Nonveiller, 1989).

Dikarenakan banyaknya jumlah sampel yang dibutuhkan untuk setiap kondisi kekasaran rekahan pada penlitian ini, serta sulitnya menemukan batuan yang memiliki kekasran rekahan yang sama di alam, maka pada penelitian ini digunakan sampel buatan yang terbuat dari material Dental Plaster. Salamian (2017) menyatakan bahwa Dental Plaster merupakan material yang baik untuk pembuatan sampel rekahan, dikarenakan material ini memiliki kekuatan yang baik, serta membutuhkan waktu yang cepat untuk proses pengeringan.

Material Grouting (Injeksi Semen) terbat dari campuran portland semen dan air, dengan perbandingan tertentu. Material injeksi dengan komposisi air : semen yang rendah memiliki nilai kuat tekan yang tinggi (Indrarata, 2000). Disisi lain, material injeksi dengan komposisi yang air:semen yang tinggi merupakan komposisi yang terbaik untuk batuan yang memiliki celah rekahan sempit (Nonveiller, 1989). Houlsby (1982) memberikan rekomendasi komposisi material grouting berdasarkan lebar bukaan rekahan seperti pada tabel 1.

Tabel 1. Rekomendasi Komposisi Material Grouting

\begin{tabular}{cc}
$\begin{array}{c}\text { Average Joint } \\
\text { Aperture }\end{array}$ & Water-Cement Ratio \\
\hline$<1$ & $3: 1$ \\
$=1$ & $2: 1$ \\
$>1$ & $1: 1$ \\
\hline
\end{tabular}

Sumber : Houlsby (1982)

Untuk rekahan batuan yang memiliki lebar bukaan kecil, Salamian (2017) menatakan bahwa semen dan air dengan perbandingan 2:1, lebih efektif menaikan kohesi batuan dibandingkan dengan semen:air 1:1, ini sekaligus membantah hasil penelitian sebelumnya yang menatakan bahwa semakin banyak kandungan semen pada material grouting, maka akan semakin tinggi kekuatannya.

Sementara itu nilai kekasaran permukaan rekahan batuan juga memiliki pengaruh yang signifikan terhadap kenaikan kekuatan geser batuan.

Pada penilitian ini, proses pembuatan sampel batuan menggunakan silicon rubber sebagai cetakan untuk mendapatan kekasaran permukaan yang sama. Silicon rubber cair dicetak ke permukaan batuan asli, selanjutnya silicon rubber yang sudah mengeras menjadi cetakan untuk sampel yang terbuat dari moldano tara.

Selanjutnya sampel yang sudah dicetak dengan nilai JRC tertentu akan dilakukan penginjeksian campuran semen dan air ke celah rekahan dengan menggunakan alat yang didesain sendiri yang terdiri atas kompresor, pipa pneumatik, kran pneumatic, dan dua buah tabung. Setiap sampel yang dibuat memiliki satu lubang di sisi atas sampel yang akan digunakan sebagai jalur untuk penginjeksian semen.

Setelah sampel diinjeksi, semua sampel akan dilaukan pengujian geser.

\section{METODE PENELITIAN}

Penelitian ini merupakan penelitian kuantitatif, karena pada penelitian ini dilakukan pengujian model yang menghasilkan data-data berupa angka yang selanjutnya dianalisis untuk mendaptkan hasil dari penelitian.

Tujuan utama dari penelitian ini adalah mempelajarai pengaruh komposisi material injeksi terhadap perubahan kekuatan geser batuan yang memiliki kekasaran permukaan (JRC) berbeda.

\section{Pembuatan sampel Artificial}

Sampel utama dibuat dengan menggunakan campuran semen dan pasir dengan ukuran pasir yang bergradasi yang diharapkan mampu memberikan perbedaan kekasaran ketika di patahkan. Sampel utama dibuat dengan bentuk silinder yang berdiameter $\pm 5,4 \mathrm{~cm}$. Setelah beberapa hari dikeringkan, sampel utama selanjutnya dipatahkan pada bagian tengah, sehingga didapatkan rekahan pada batuan sampel yang memiliki kekasaran berbeda. Sehingga didapatkan sampel utama seperti gambar 1 . 


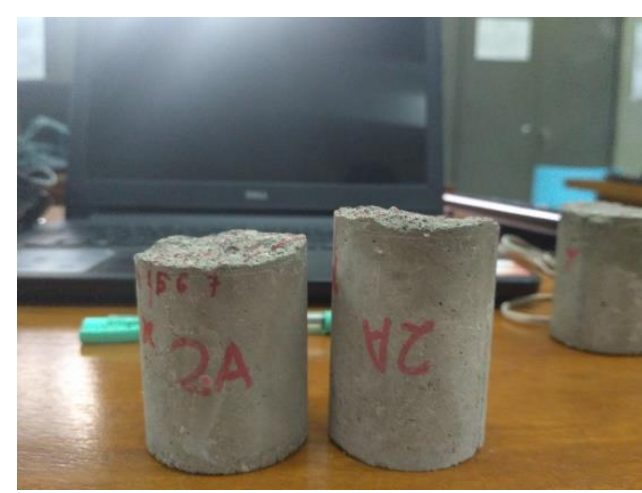

Gambar 1. Sampel Utama

Kekasaran permukaan rekahan selanjutnya diukur dengan menggunakan sisir barton (Barton Comb) sehingga didapatkan tiga nilai kekasaran. Masing-masing sampel yang memiliki kekasaran permukaan berbeda selanjutnya dicetak ke sampel buatan yang terbuat dari material moldano tara.

Pencetakan kekasaran permukaan mengunakan material silicon rubber cair yang dicetak menggunakan kekasaran sampel utama, selanjutnya silicon rubber menjadi cetakan (molding) untuk sampel buatan lainnya.

Cara ini dipilih mengingat pada kondisi alamiah sangat sulit untuk menemukan batuan dengan kekasaran rekahan yang bernilai sama dalam jumlah yang banyak. Sementara penilitian ini membutuhkan banyak sampel, dimana masing-masing nilai JRC membutuhkan \pm 9 buah sampel untuk diuji.

Moldano Tara dipilih sebagai bahan pembuatan sampel buatan dikarenakan material ini memiliki kekuatan tekan yang cukup baik dengan nilai $17.93 \mathrm{MPa}$, material ini juga membutuhkan waktu yang singkat pada proses pencetakan, dalam waktu 15 menit sampel sudah bisa dilepas dari cetakan, serta hanya dibutuhkan waktu 7 hari untuk mencapai kekuatan maksimalnya. Hasil silicon rubber yang digunakan sebagai cetakan dan hasil cetakan sampel artificial dapat dilihat pada gambar 2.

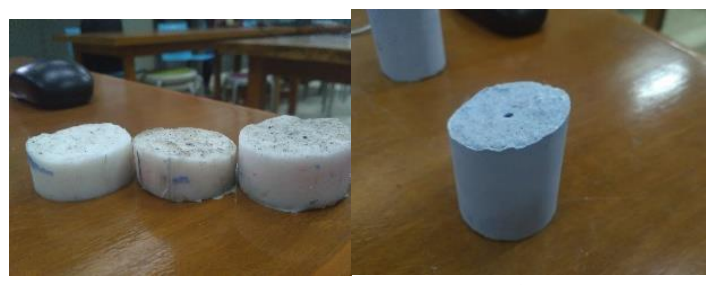

(a)

(b)

Gambar 2. (a) cetakan dari silicon rubber (b) Hasil cetakan sampel artificial

2. Pegukuran Nilai JRC
Penentuan nilai JRC dilakukan dengan menggunakan Barton Comb untuk mendapatkan kontur permukaan rekahan, selanjutnya kontur perukaan rekahan didigitasi pada kertas milimeter blok. Hasil digitasi berupa beda tinggi setiap satuan panjang yang selanjutnya dihitung dengan persamaan yang dihasilkan oleh Li dan Zhang (2015), sehingga dapat dihitung nilai JRC sebagai berikut :

$$
\begin{aligned}
& I R C=137,1739(S F)^{0,5}-3,9998 \\
& S F=\frac{\sum_{i-0}^{n-1}\left(y_{i+1}-y_{i}\right)^{2}+\left(x_{i+1}-x_{i}\right)}{L}
\end{aligned}
$$

Dengan nilai $\mathrm{x}$ dan y didapat dari hasil digitasi pada gambar 3 .

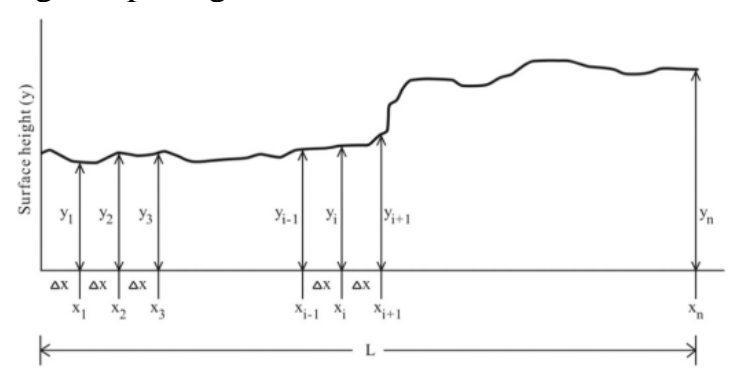

Gambar 3. Prameter Statistik Profil Rekahan

Jika penampang sampel yang digunakan berukuran lebih kecil daripada penampang Barton, maka diperlukan faktor koreksi, sehingga nilai JRC menjadi:

$$
I R C_{n}=J R C_{0}\left[\frac{L_{n}}{L_{0}}\right]^{-0,02 J R C_{0}}
$$

Dari persamaan di atas, maka didapatkan nilai JRC untuk masing masing sampel sebagai berikut :

Table 2. Nilai JRC masing-masing sampel

\begin{tabular}{cc}
\hline Kode Sampel & Nilai JRC \\
\hline JRC 1 & 9,0 \\
JRC 2 & 13,4 \\
JRC 3 & 16,1 \\
JRC 4 & 18,1 \\
\hline
\end{tabular}

Dalam penilitian ini menggunakan 4 sampel dengan variasi nilai JRC yang berkisar antara 9,0-18,1.

\section{Penginjeksian Semen}

Dua variasi komposisi semen dan air digunakan pada penelitian ini, komposisi pertama 4 air : 5 semen (4W:5C) dan komposisi kedua lebih encer dengan 
perbandingan 3 air : 2 semen. Material grotuing selanjutnya di injeksikan ke dalam rekahan batuan dengan menggunakan rangkaian alat kompresor, botol, dan pipa pneumatic, seperti pada gambar 4.

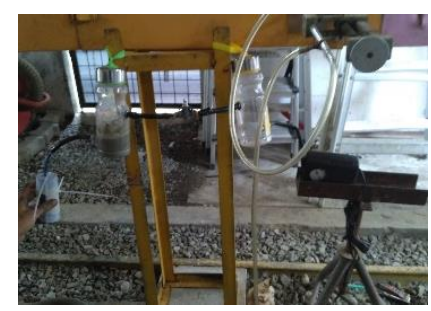

(a)

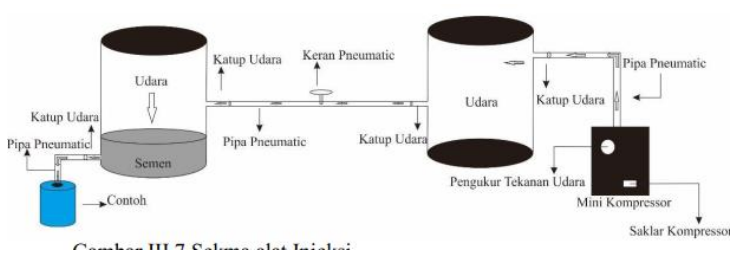

(b)

Gambar 4. (a) Proses Injeksi Semen ke Rekahan Batuan (b) Skema alat Injeksi

Material grouting di injeksikan dengan tekanan sebesar 1 bar, tekanan ini dikontrol dengan barometer yang terpasang pada kompresor. Kran pneumatic dipasang agar tekanan yang ada pada tabung tetap sebesar 1 bar. Masing-masing material injeksi yang digunakan mempunyai properties sebagai berikut :

Tabel 3. Sifaat Mekanik Material Injesi

\begin{tabular}{ccccc}
\hline No & $\begin{array}{c}\text { Sample } \\
\text { Code }\end{array}$ & $\begin{array}{c}\sigma c \\
(\mathrm{MPa})\end{array}$ & $\begin{array}{c}\mathrm{E} \\
(\mathrm{MPa})\end{array}$ & $v$ \\
\hline 1 & $4 \mathrm{~W}: 5 \mathrm{C}$ & 12.44 & 2534.12 & 0.30 \\
2 & $3 \mathrm{~W}: 2 \mathrm{C}$ & 5.86 & 1212.17 & 0.34 \\
\hline
\end{tabular}

Peralatan penginjeksi terdiri atas satu buah mini kompresor, dua buah botol vakum, pipa pneumatic, kran pneumatic, dan dua katup udara. Alat ini bekerja dengan cara, kompresor mengalirkan udara pada tabung kedap pertama, hingga tekanan udara pada tabung pertama sebesar 1 bar, lalu kran pneumatic dibuka perlahan agar tekanan udara tetap 1 bar, aliran udara selanjutnya mengalir ke tabung kedua ang berisikan material injeksi, sehingga material injeksi yang ada pada tabung kedua terdorong masuk menuju celah rekahan dengan tekanan sebesar 1 bar.

Selama proses penginjeksian bagian atas dan bawah sampel diikat dengan menggunakan cable tie, agar celah rekahan tidak bertambah lebar ketika diberi material injeksi bertekanan, setelah dilakukan penginjeksian sampel didiamkan selama 28hari agar material injeksi mencapai kekuatan maksimal.

\section{Uji Geser Langsung}

Uji geser langsung yang dilakukan pada penelitian ini menggunakan gaya normal konstan (constant normal load). Pengujian dilakukan di laboratorium geomekanika dan peraltan tambang Institut Teknologi Bandung. Masing-masing set sampel di uji sebanyak 5 buah dengan variasi gaya normal $0,2 \mathrm{kN} ; 0,4$ $\mathrm{kN} ; 0,6 \mathrm{kN} ; 0,8 \mathrm{kN}$; dan $0,89 \mathrm{kN}$. Mengacu pada kriteria keruntuhan Mohr-Coloumb dari hasil uji geser langsung ini akan didapatkan nilai Kohesi (C) dan sudut gesek dalam $(\phi)$, sebagai parameter dari kekuatan geser batuan berkekar.

\section{HASIL DAN PEMBAHASAN}

Hasil dari uji geser langsung selanjutnya dianalisis menggunakan kriteria MohrColoumb dan kriteria Barton-Bandis. Kriteria Barton-Bandis digunakan pada sampel batauan berkekar yang tidak di injeksi material semen, sementara sampel yang diinjeksi material semen menggunakan kriteria Mohr-Coloumb.

1. Kriteria Barton-Bandis

Kriteria Barton-Bandis menghitung nilai kuat geser batuan berkekar dengan mengakomodir keberadaan kekasaran rekahan, sehingga kuat geser batuan didefinisikan sebagai :

$$
\tau=\sigma_{n} \tan \left(J R C \log 10\left(\frac{J C S}{\sigma_{n}}\right)+\phi_{r}\right)
$$

Selanjutnya untukmendapatkan nilai sudut gesek dalam residual dari sampel batuan berkekar dilakukan plotting hasil pengujian terhadap ktiteria Barton-Bandis, seperti berikut 


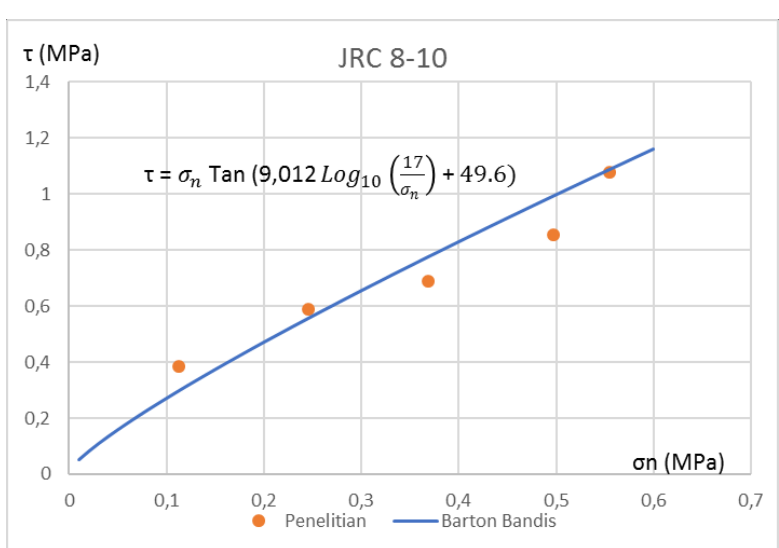

Gambar 5. Plotting hasil pengujian Terhadap Kriteria Barton-Bandis Nilai JRC 8-10

Dari hasil plotting diatas, maka didapatkan nilai sudut geser dalam residual untuk masing-masing kelompok sampel, yang besarnya :

Tabel 4. Nilai sudut gesek dalam residu BartonBandis

\begin{tabular}{rrr}
\hline Sampel & \multicolumn{1}{c}{ JRC } & $\phi \mathrm{r}\left(^{\circ}\right)$ \\
\hline 1 & 9,0 & 49,6 \\
2 & 13,4 & 42,3 \\
3 & 16,1 & 39,6 \\
4 & 18,1 & 39,1 \\
\hline
\end{tabular}

Untuk mengetahui seberapa akurat hasil plotting maka dilakukan perhitungan nilai koefisien korelasi, root means square error, dan varians

Table 5. Parameter Statistik

\begin{tabular}{llll}
\hline Sampel & RMSE & VAF & $\mathrm{R}^{2}$ \\
\hline JRC 1 & 0.09 & $88 \%$ & 0.96 \\
JRC 2 & 0.10 & $84 \%$ & 0.91 \\
JRC 3 & 0.09 & $90 \%$ & 0.93 \\
JRC 4 & 0.05 & $97 \%$ & 0.97 \\
\hline
\end{tabular}

Dari parameter statistik terlihat bahwa hasil persamaan Barton-Bandis hampir mendekati hasil pengujian laboratorium hasil ini diindikasikan dengan nilai koefesien korelasi yang > 0.9, dan nilai RMSE dan VAF yang sudah mendekati hasil uji.

\section{Non-Linier Barton Bandis}

Untuk mendapatkan nilai kohesi dan sudut geser dalam puncak dari sampel batuan berkekar perlu dilakukan konversi menggunakan persamaan yang ditemukan oleh
Simon (2017) yang mendefinisikan sudut gesek dalam puncak sebagai :

$\tan \phi_{t}=\tan \left[J R C \log _{10}\left(\frac{J C S}{\sigma_{n}}\right)+\phi_{r}\right]-\left(1+A^{2}\right) \frac{J R C}{\ln _{10}}$ Sementara kohesi puncak dapat dihitung dengan persamaan :

$$
\begin{aligned}
& C_{t}=\sigma_{n} B \\
& \mathrm{~A}=\tan \left[j R C \log _{10}\left(\frac{j C 5}{\sigma_{n}}\right)+\phi_{r}\right] \\
& \mathrm{B}=\left(1+A^{2}\right) \frac{J R C}{\mathbb{l n}_{10}}
\end{aligned}
$$

Sehingga dari persamaan ini dapat ditentukan nilai kohesi dan sudut gesek dalam puncak sebagai berikut :

Tabel 6. Kohesi dan Sudut Gesek Dalam Puncak Batuan Berkekar

\begin{tabular}{ccc}
\hline JRC & $\begin{array}{c}\text { Cohesion } \\
(\mathrm{MPa})\end{array}$ & $\begin{array}{c}\text { Internal } \\
\text { Friction Angle } \\
\left({ }^{\circ}\right)\end{array}$ \\
\hline 1 & 0.100 & 62.02 \\
2 & 0.181 & 58.83 \\
3 & 0.266 & 58.00 \\
4 & 0.401 & 57.00 \\
\hline
\end{tabular}

Dari tabel di atas dapat dilihat nilai kohesi dan sudut gesek dalam puncak untuk sampel batuan berkekar, sehingga bisa dibandingkan dan dilihat eprubahan nilai akibat penggunaan injeksi semen.

3. Kurva Hubungan Gaya Normal dan Kuat Geser

Kurva dibuat berdasrakan nilai JRC masing-masing sampel, di dalam kurva menjelaskan nilai kuat geser puncak dan kuat geser residu dari masing masing sampel. Dalam satu kurva akan terdapat 6 buah garis yang menghubungkan 5 titik masingmasingnya, ini merupakan hasil plotting dari kuat geser masing-masing kondisi sampel yang terdiri atas, sampel batuan berkekar, sampel batuan diinjeksi dengan rasio $4 \mathrm{~W}: 5 \mathrm{C}$, dan sampel batuan diinjekasi dengan rasio $3 \mathrm{~W}: 2 \mathrm{C}$.

Kemiringan garis merupakan sudut geser dalam dari sampel batuan, sementara perpotongan garis dengan sumbu $\mathrm{Y}$ merupakan nilai kohesi dari sampel batuan tersebut, hal ini berlaku untuk kondisi puncak maupun residual. 


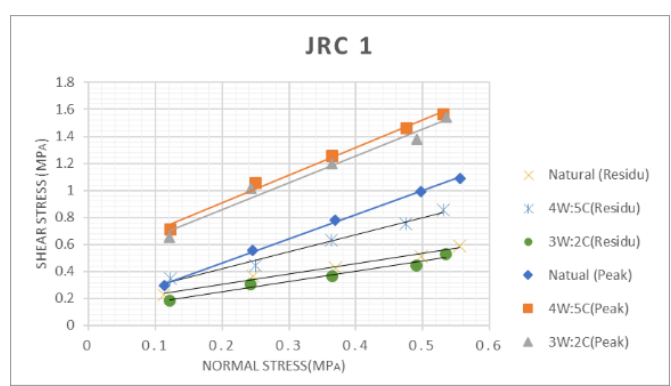

(a)

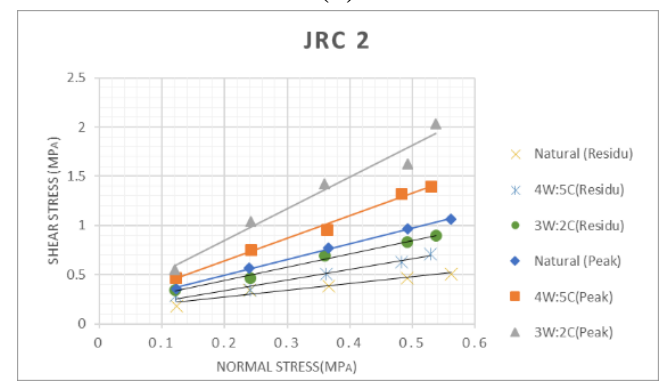

(b)

Gambar 6. Kurva tegangan Normal dan tegangan Geser (a) JRC 1 (b) JRC 2

Kurva diatas menjelaskan hubungan linear antara tegangan normal dan tegangan geser, serta bisa menentukan nilai kohesi dan sudut gesek dalam. Dalam kondisi residual nilai kohesi tidak mendekati nol, ini karena adanya pengaruh penggunaan injeksi semen, sehingga merubah karakter batuan tersebut. Pada gambar 6 terlihat bahwa penggunaan injeksi semen pada batuan berkekar memberikan perubahan terhadap kekuatan geser batuan, dimana untuk kondisi JRC 1 campuran semen:air 4W:5C lebih efektif menaikkan kekuatan geser batuan berkekar jika dibandingkan dengan material injeksi berkomposisi 3W:2C.

Untuk sampel dengan JRC 2 material injeksi dengan komposisi 3W:2C lebih efektif dibandingkan dengan material injeksi dengan komposisi 4W:5C.

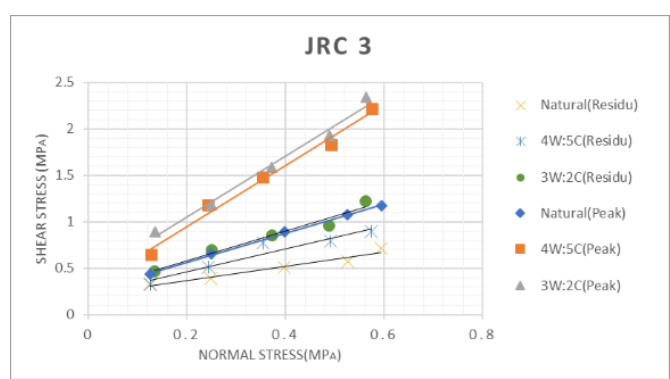

(a)

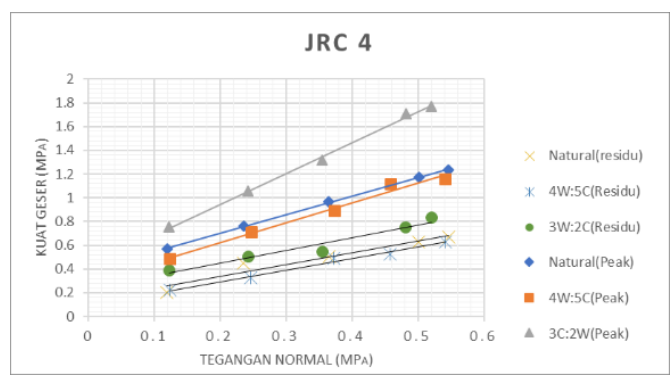

(b)

Gambar 7. Kurva tegangan Normal dan tegangan Geser (a) JRC 3 (b) JRC 4

Untuk sampel JRC 3 dan JRC 4 material injeksi dengan komposisi air:semen 3:2 lebih efektif untuk menaikkan kekuatan geser batuan, namun ada hal unik yang terjadi pada sampel JRC 4, dimana batuan berkekar yang diinjeksi dengan campuran air:semen 4:5 mengalami penurunan kekuatan geser, hal ini mengindikasikan permukaan rekahan yang tidak tertutup sempurna oleh material injeksi yang lebih kental.

Pengaruh kekentalan komposisi material injeksi terhadap efektifitas penginjeksian dapat diihat pada gambar 8 . 


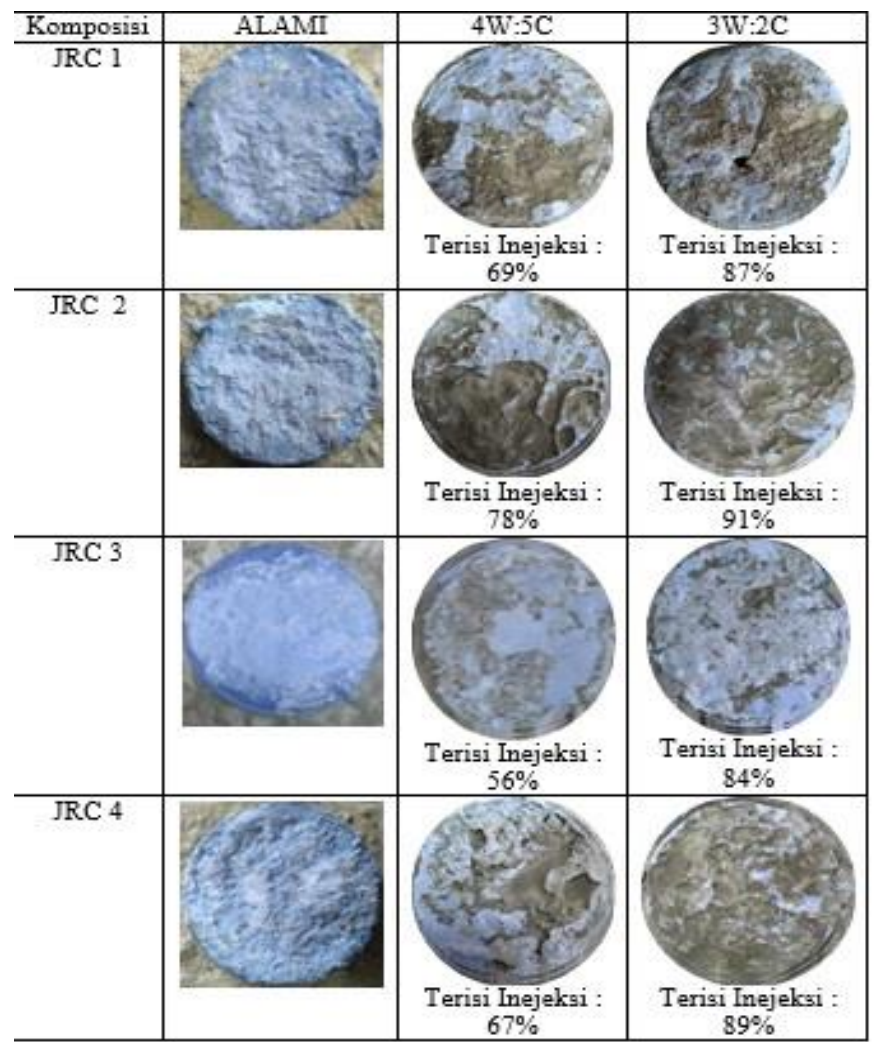

Gambar 8. Kondisi Rekahan Setelah diinjeksi

Terlihat semen dengan campuran yang lebih encer $3 \mathrm{~W}: 2 \mathrm{C}$ mampu lebih efektif mengisi celah rekahan pada batuan. Namun pada kondisi permukaan rekahan yang lebih rata, kekuatan material injeksi lebih berpengaruh jika dibandingkan dengan luas area isiannya.

4. Perubahan Nilai Kohesi dan Sudut Gesek Dalam

Sebagai pengaruh dari injeksi semen pada batuan berkekar, terjadi perubahan nilai kohesi dan sudut geser dalam batuan yang berubah berdasarkan komposisi material injeksi dan nilai JRC masing-masing sampel.

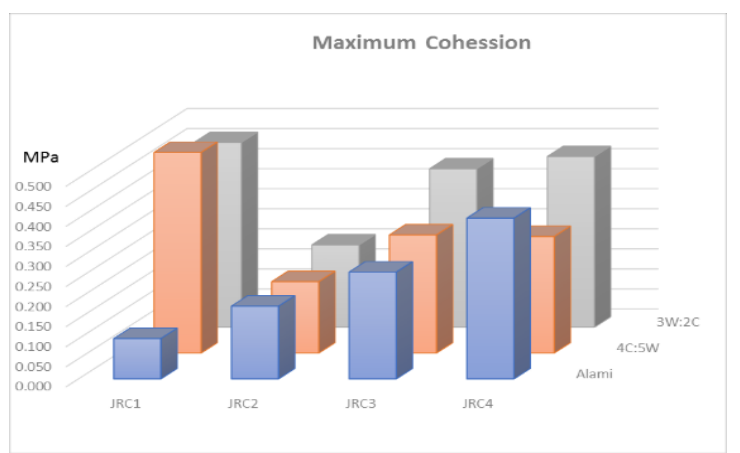

(a)

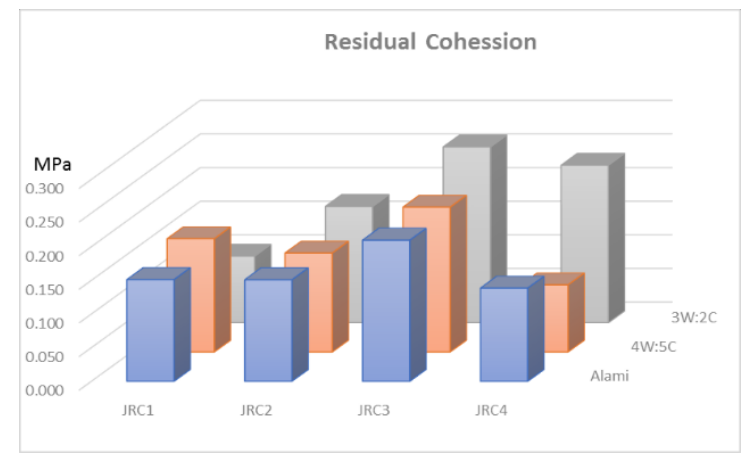

(b)

Gambar 9. Perubahan nilai kohesi (a) kondisi puncak (b) kondisi residual

Gambar 9 (a) menggambarkan perubahan nilai kohesi puncak antara batuan berkekar dengan batuan berinjeksi, terlihat bahwa semakin tinggi nilai JRC, maka nilai kohesi juga semakin meningkat, sementara gambar 9 (b) merupakan perubahan nilai kohesi residual, dari gambar tersebut dapat disimpulkan bahwa nilai JRC tidak mempengaruhi nilai kohesi residual.

Sementara untuk perubahan nilai sudut gesek dalam adalah sebagai berikut : 


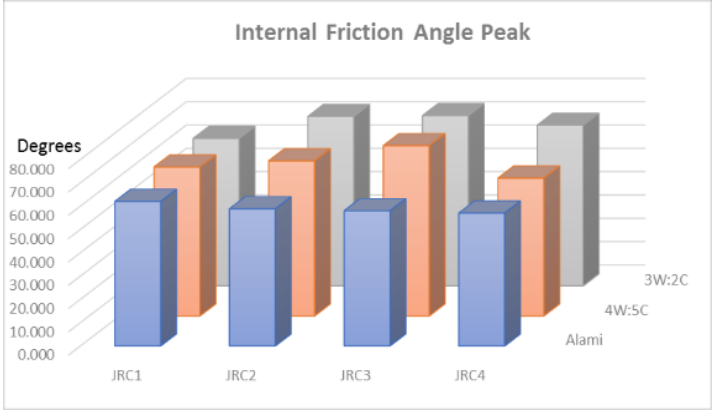

(a)

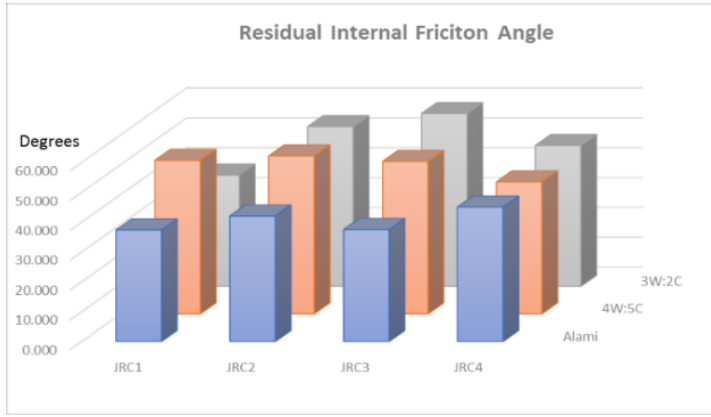

(b)

Gambar 10. Perubahan nilai sudut geser dalam (a) Kondisi puncak (b) Kondisi Residual

Berbeda dengan nilai kohesi yang semakin meningkat seiring dengan peningkatan nilai JRC, nilai sudut gesek dalam akan menurun seiring dengan penigkatan nilai JRC.

\section{KESIMPULAN}

Berdasarkan hasil penelitian yang dilakukan dapat disimpulkan bahwa, kekuatan geser batuan berkekar akan meningkat seiring dengan peningkatan nilai JRC. Penggunaan injeksi semen pada celah batuan berkekar akan merubah karakteristik batuan tersebut. Komposisi material injeksi yang digunakan akan mempengaruhi perubahan kekuatan geser batuan, perubahan kekuatan geser akibat pemberian injeksi juga dpengaruhi oleh kondisi kekasaran permukaan rekahan.

Untuk sampel yang memiliki nilai JRC 810 yang memiliki kode sampel JRC 1, mengalami kenaikan kekuatan geser yang lebih tinggi jika diberikan injeksi dengan komposisi material 4W:5C. Sementara untuk sampel dengan nilai JRC 12-14 dengan kode sampel JRC 2, JRC 16-18 dengan kode sampel JRC 3, dan 18-20 dengan kode sampel JRC 4, mengalami kenaikan kekuatan geser paling optimal ketika diinjeksi dengan kompoisi material injeksi 3W:2C.

Merujuk buku Grouting Theory and Practice (1989), maka berikut rekomendasi komposisi material injeksi berdasarkan penelitian ini :

Tabel 7. Rekomendasi material injeksi berdasarkan nilai JRC

\begin{tabular}{|c|c|c|}
\hline $\begin{array}{c}\text { Lebar Celah } \\
\text { Rekahan Rata- } \\
\text { rata } \\
(\mathrm{mm})\end{array}$ & $\begin{array}{c}\text { Nilai } \\
\text { JRC }\end{array}$ & $\begin{array}{c}\text { Perbandingan } \\
\text { Air : Semen }\end{array}$ \\
\hline$<1$ & - & $3: 1$ \\
\hline \multirow{4}{*}{$\approx 1$} & $18-20$ & \multirow{2}{*}{$3: 2$} \\
\cline { 2 - 2 } & $16-18$ & \\
\cline { 2 - 3 } & $12-14$ & \\
\cline { 2 - 3 } & $8-10$ & $4: 5$ \\
\hline$>1$ & - & $1: 1$ \\
\hline
\end{tabular}

Penelitian ini masih terbatas pada empat kondisi kekasaran permukaan dengan rata-rata lebar celah rekahan batuan $\approx 1 \mathrm{~mm}$.

\section{DAFTAR PUSTAKA}

Bandis S., Lumdsen, A.C., Barton, N.R Experimental Studies of Scale Effect on Shear Behaviour of Rock Joint, International Journal Rock Mechanics, Mining Science, and Geomechanics, 18, 1-21.(1981).

Barton, N., Bandis, SRock Joints, Barton and Stephenson, Rotterdam: Balkema. .(1980)

Hoek, E., Torres, C.C., Corkum, B, HoekBrown Failure Criteria-2002 Edition, Canada: Rocscience.(2012)

Houlsby, A.C, Optimum Water:Cement Ratio for Rock Grouting, CGGE, New Oerlans, 317-331.(1982)

Hudson, J.A., Harrison, J.P., Engineering Rock Mechanics an Introduction to The Principles, Great Britain: Pergamon.(1997)

Li, Y., Zhang, Y., Quantitative Estimation of Joint Roughness Coefficient Using Statistical Parameters, International Journal of Rock Mechanics and Mining Sciences, 77, 27-35.(2015) 
Lombardy, G., The Role of Cohesion in Cement Grouting of Rock, XVth, ICOLD, Lausanne, 3, 235262.(1985)

Nonveiller, N., Grouting Theory and Practice, Amsterdam : Elsavier.(1989)

Prasettyo, S.H., Gutierrez, M., Barton, N., Nonliniear Shear Behaviour of Rock Joint using Linierazed Implementation of The BartonBandis Model, Journal of Rock Mechanics and Geotechnical Engineering, 9, 671-682.(2017)

Rai, M.A., Wattimena, R.K., Karmadibrata,S., Mekanika Batuan, Bandung: ITB Press (2012)

Salamian, et., all., Effect of Grouting on Shear Behaviour of Rock Joint, International Journal of Rock Mechanics and Mining Sciences, 98, 159-166.(2017)

Wyllie, D.C., Mah, C.W., Rock Slope Engineering Civil and Mining, London: Spon Press (2005)

Zakri, RS., GM Simangunsong, NP Widodo, Effect of Cement Injection on Shear Behaviour of Jointed Rock based on Mohr-Coulomb Criterion, Proceeding The International Symposium on Earth Science and Technology, 671-676. (2018)

Zheng, B., Qi, S., A New Index to Describe Joint Roughness Coefficient (JRC) Under Cyclic Shear, Engineering Geology, 212, 72-85. (2016) 